ALDEN

UNIVERSITY

A higher degree. A higher purpose.

Walden University ScholarWorks

\title{
How Does Organizational Culture Impact RN Engagement
}

Veronica Anntionette Ruffin-Ellis

Walden University

Follow this and additional works at: https://scholarworks.waldenu.edu/dissertations

Part of the Business Administration, Management, and Operations Commons, Health and Medical Administration Commons, Management Sciences and Quantitative Methods Commons, and the Nursing Commons

This Dissertation is brought to you for free and open access by the Walden Dissertations and Doctoral Studies Collection at ScholarWorks. It has been accepted for inclusion in Walden Dissertations and Doctoral Studies by an authorized administrator of ScholarWorks. For more information, please contact ScholarWorks@waldenu.edu. 


\title{
Walden University
}

\author{
College of Health Sciences
}

This is to certify that the doctoral study by

Veronica Ruffin-Ellis

has been found to be complete and satisfactory in all respects, and that any and all revisions required by the review committee have been made.

Review Committee

Dr. Dana Leach, Committee Chairperson, Health Services Faculty

Dr. Amy Wilson, Committee Member, Health Services Faculty

Dr. Jonas Nguh, University Reviewer, Health Services Faculty

Chief Academic Officer

Eric Riedel, Ph.D.

Walden University

2017 


\begin{abstract}
A Proposal for the Implementation of a Registered Nurse Engagement Program

by

Veronica Ruffin-Ellis
\end{abstract}

MS, RN, Ed., The College of New Rochelle, 2010

BSN, The College of New Rochelle, 2005

Project Submitted in Partial Fulfillment

of the Requirements for the Degree of

Doctor of Nursing Practice

Walden University

May 2017 


\begin{abstract}
Lack of RN engagement in the acute care setting can result in poor staffing, nursing shortages, increased stress levels for nurses and decreased morale. When nurses are not engaged in their work setting, quality of care suffers. A wide range of literature focuses on the importance of $\mathrm{RN}$ engagement; however, few health care organizations have taken the initiative to implement programs that foster RN engagement, demonstrating a gap in practice. This study examined the relationship between the levels of RN engagement and their perceptions of their organizational culture. Kolcaba's humanistic approach to meeting the needs of $\mathrm{RN}$ staff was used to guide the study by recognizing that when nurses' needs are met, a culture of positive interactions between nurses and patients enhances the quality of care delivered. The project question addressed existing levels of RN engagement and perceptions of organizational culture in a small community hospital in New York. All full-time registered nurses employed at the organization completed the 2 surveys used for this qualitative, exploratory project. RN engagement was measured using the NDNQI RN engagement survey in combination with an organizational driven interim survey. Data were explored for patterns and the project results indicated that quality of care improved when nurses were engaged in hospital affairs, staffing, and resource adequacy. Social change is impacted when a commitment to $\mathrm{RN}$ engagement is established and the engaged caregivers influence improvements in quality of care and patient care outcomes.
\end{abstract}


A Proposal for the Implementation of a Registered Nurse Engagement Program

Organizations

by

Veronica Ruffin-Ellis

MS, The College of New Rochelle, 2010

BS, The College of New Rochelle, 2005

Project Submitted in Partial Fulfillment

Of the Requirements for the Degree of

Doctor of Nursing Practice

College of Health Sciences

Walden University

May 2017 


\section{Dedication}

Jeanette, Blanche and Sharon, you are the makings of me! To my husband Eric, you have always encouraged me to soar. Donnice, my baby girl, you have always been the wind beneath my wings. Elice, I could not ask for a prettier princess who has such a big heart. Jaylin, you are an old soul that constantly reminds me that as a parent, I must demonstrate role model behavior. I hope my journey inspires my children, nieces and nephews to always pray, have faith, dream big and work hard knowing...GOD will do the rest! 


\section{Acknowledgments}

To my sisters, my “sister girlz", and my brothers, for appreciating me, and the work that I do. There are no words that can adequately describe your place in my heart.

To Thelma Green and Johnny Mae Stokes, you were my foundational rocks!

To my Calvary Hospital family, YOU taught me how to be a leader. To my dedicated $6^{\text {th }}$ floor team, thank you for your commitment to caring for others with your heart and soul. You've inspired my ability to achieve this lifetime dream.

To my fellow DNP students, I've learned so much from you all; I appreciate your knowledge and support when this journey seemed long.

To Dr. Dana Leach, every time I think of those moments when I was going left, you steered me right with your patience, kind words, encouraging tone (even if it was via email). I am overwhelmed with gratitude and appreciation for having you by my side, holding me up and reminding me that, I could do this!

In addition, I want to thank Kathy Webster, Marie Galant \& the NYPHVH Nursing Education team, Alice Corbett and Dr. Tallier for their support in my practicum environment. Kathy Geaney and the 4 south team, your unwavering support is priceless. 


\section{Table of Contents}

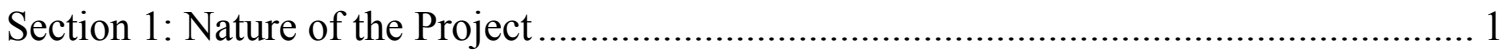

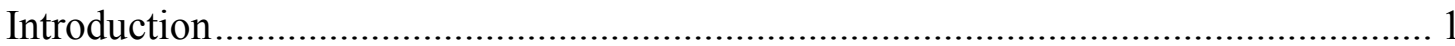

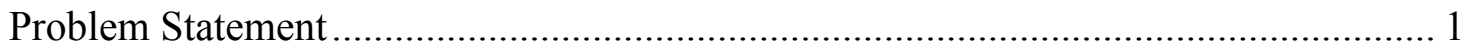

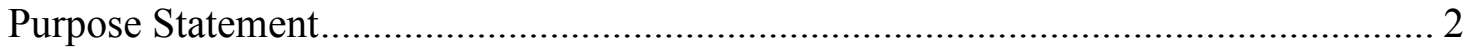

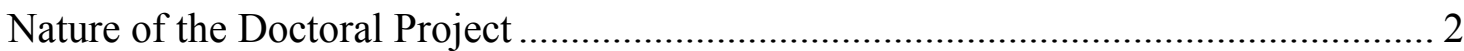

Guiding, Practice, and Research Questions ........................................................ 3

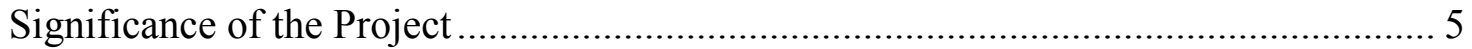

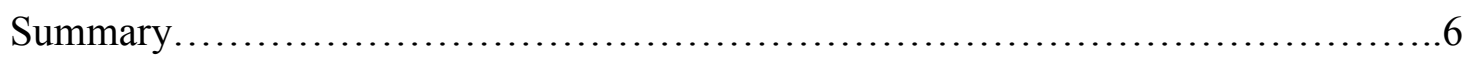

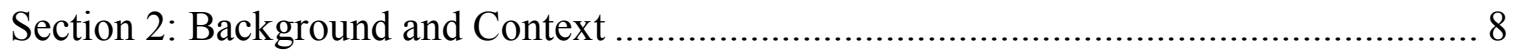

Concepts, Models, and Theories ............................................................................ 8

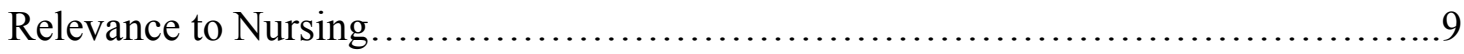

Local Background and Context................................................9

Role of the DNP Student................................................ 10

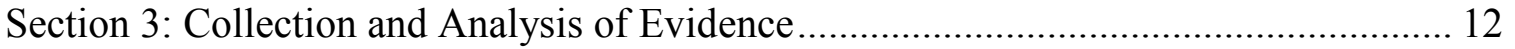

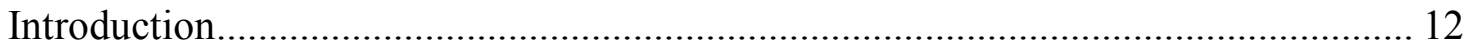

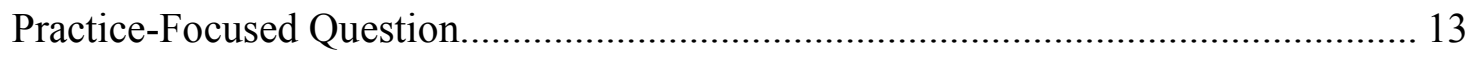

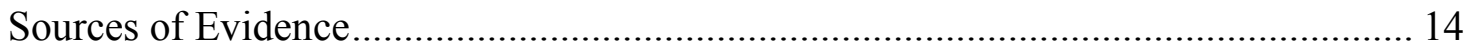

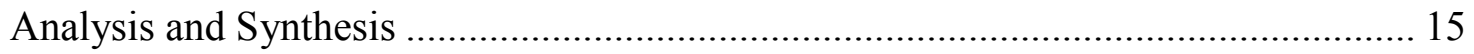

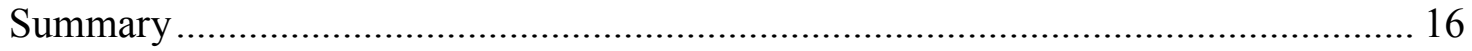

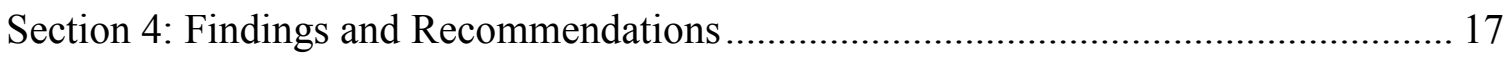




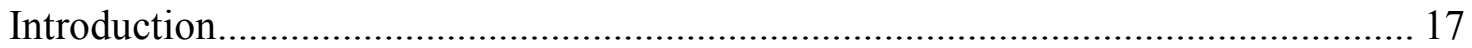

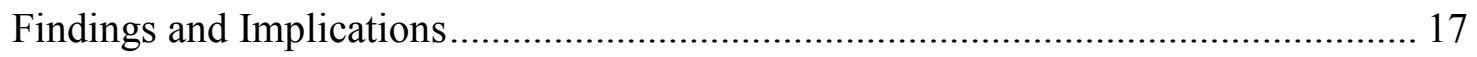

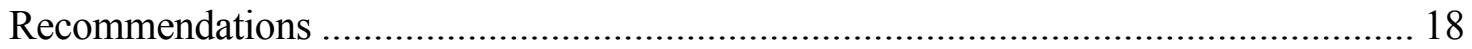

Strengths and Limitations of the Project................................................................. 18

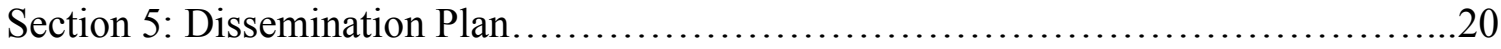

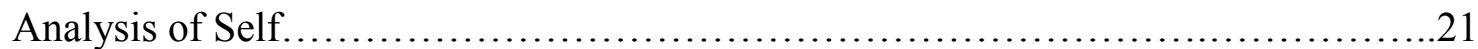

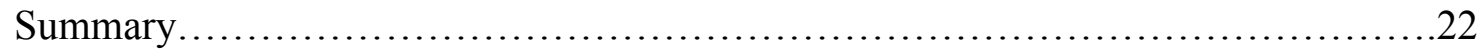

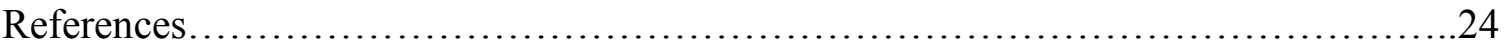




\section{Section 1: Nature of the Project}

\section{Introduction}

From the bedside, outpatient areas, in academia, the board rooms, and in policy forums, it is essential for Registered Nurses $(\mathrm{RN})$ to be engaged in order for health care to be successful (Bodenheimer \& Grumbach. 2012). The concept of engagement in health care has developed over the past decade. Keeping employees engaged in their roles is essential to the success of any organization (Bakker \& Demerouti, 2008). Health care reform and the Centers for Medicare and Medicaid Services have mandated health care organizations to provide their consumers with safe, quality, effective care (Ball et al., 2011). Regulatory agencies such as the National Database for Nursing Quality Indicators (NDNQI) and the Institute of Medicine (IOM) have both acknowledged the implications of RN engagement in health care (IOM, 2010). A work environment that consistently lives its mission, vision and culture, and demonstrates respect and support for the RN staff, will foster an environment where RNs are loyal and engaged. The culture of a health care organization contributes to their ability to recruit and retain RNs who are engaged (Lambrou et al., 2014).

\section{Problem Statement}

The culture of a health care organization can greatly influence its ability to motivate and retain RNs who are loyal and engaged (Manley, Sanders, Cardiff, and Webster, 2011). When the culture is lived daily, employee trust is reinforced (White \& Dudley-Brown, 2012).

Burston and Stichler (2010) emphasized nurse satisfaction in relation to stress, burnout, and compassion fatigue. Poor staffing and nursing shortages add to the stress levels, decreasing morale and engagement. The Institute of Medicine (IOM) notes RNs are an essential part of the health care workforce, recommending they be full partners, with all disciplines, and identify 
problems, and establishing goals (IOM, 2010). It is important administration respects and supports the RN discipline as collaborative team members, welcoming them to participate in important decision making that impacts patient care and outcomes (Pfaff, Baxter, Ploeg, and Jack, 2013). In order to retain quality RNs, health care organizations should assess how their culture influences RN engagement.

\section{Purpose Statement}

Health care is constantly changing, forcing health care organizations to become more strategic and competitive in how they deliver health care (Kotter, 2007). With RNs being the primary and perhaps the most influential caregivers, it is imperative that health care organizations create a culture where RNs are made to feel like important stakeholders (Bodenheimer \& Grumbach, 2012). The long-term purpose of this project is to demonstrate the importance of organizational culture and its impact on $\mathrm{RN}$ engagement. Due to the time constraints, I will request an evaluation of the recommended RN engagement program by five experts in the related field. The evaluation tool is a five question Likert scale evaluating the proposed program.

\section{Nature of the Doctoral Project}

The main objective of this project was to share the idea of a proposed $\mathrm{RN}$ engagement program that would demonstrate respect and value for organizational culture and its influence on $\mathrm{RN}$ engagement. The development of an $\mathrm{RN}$ engagement program that supports this endeavor may meet the objective of better administrative and $\mathrm{RN}$ relationships (Tomey, 2009). This can be measured by nurse attendance and participation at these forums. This objective will be measured and may show evidence from in-hospital surveys and NDNQI RN surveys. 
A long-term objective is to sustain a successful $\mathrm{RN}$ engagement program that could be shared with other health care organizations, especially those seeking Magnet designation locally and abroad. Magnet designation by the American Nurses Credentialing Center (ANCC) is a designation granted based upon nursing excellence within an organization. The engagement of the Registered Nurse is imperative in order for a health care organization to meet the tenets of Magnet which include: structural empowerment, transformational leadership, exemplary professional practice, new knowledge and innovations, as well a research resulting in evidence based practices. Publishing the details of the development and successful implementation and sustainment of such a program would reach stakeholders who share the same goals (Oerman, 2016).

\section{Guiding, Practice, and Research Questions}

While health care requires an interdisciplinary team approach, it is often the RNs who have the greatest influence on a patient's experience, often determining whether or not the patient trusts the care being rendered and was satisfied with their overall experience (Tillot, et al., 2013). The concept of RN engagement in health care continues to develop (Manley, Sanders, Cardiff, \& Webster, 2011). In previous literature, Manley notes 10 core values that focus on interpersonal relationships and RN engagement:

- An environment where lifelong learning is promoted

- Leadership is developed,

- Stakeholder involvement in decision making processes

- Evidence Based Practice (EBP) is promoted

- Commitment to change and innovation,

- Open, respectful communication 
- Teamwork

- Safety

When these core values are present, RNs feel a sense of importance and belonging. The ability to obtain and retain loyal RNs, sustaining engagement, is essential to the success of health care organizations (Harmon, et al., 2010).

The United States has a shortage of nurses that is estimated to increase to over 200,000 by the year 2025 (Crum, 2014). Ginter (2014), DNP student at Walden University noted in her dissertation the challenges of novice nurses being able to think critically and collaborate with other disciplines. Ginter highlighted the importance of providing education, mentoring, coaching, leadership building, and improved communication to ensure a smooth transition into the professional role and facilitate the retention of these novice nurses. This organized program provided some of the essential core values noted by Manley, et al. (2011).

In consideration of an aging and health care savvy population, the supply and demand of RNs is of major concern.

RNs and patients are considered internal and external customers. Both have choices in which health care organization is going to best meet their needs (Collins et al., 2008). A healthy relationship amongst RN staff and administration make a work environment enjoyable, while ultimately positively affecting the organizations bottom line. Engaged and loyal employees will affect the organizations bottom line as it relates to (Jones \& Gates, 2007, Schifalacqua et al., 2011):

- Vacancy costs

- Recruitment costs

- Hiring costs 
- Orientation \& Training costs

- Termination costs

What sacrifices are health care organizations willing to make in order to ensure that their RN staff are present and engaged?

\section{Significance of the Project}

Safe, quality, effective care has been declared mandatory by various regulatory agencies and accrediting associations. The 2010 Affordable Care Act supported this same declaration (IOM, 2010). Nurses work well beyond their expected hours to ensure quality care is rendered. While mandatory overtime is not universal, it presents genuine concerns and repercussions that impact the health of the nurse and safety of the patients (Bae, \& Brewer, 2010). Some of these repercussions include sick calls and burn out (Bae, 2012).

The current state of nursing is quite different than that of the past. With the baby boomer generation living longer, there is a lack of balance between the population and supply of nurses

to care for them. Safe staffing has to be a priority (Bodenheimer \& Grumbach, (2012).

As nurse leaders, we are responsible for leading innovation and impacting change in health care. This is easily made possible when health care environments are focused on improving their culture and supporting the needs of RNs (Hyrkas et al., 2010). These matters are important to the RN staff. Health care organizations strive to demonstrate excellence in quality care. The magnet model demonstrates excellence in nursing care and patient outcomes. While there are 22 health care organizations and systems that have obtained Magnet designation in the New York area, it continues to be the goal for others. The tenets of Magnet include structural empowerment, transformational leadership, exemplary professional practice and new knowledge and innovations. These tenets encompass the same attributes, which foster RN 
engagement, noted by Manley (2011).

$\mathrm{RN}$ staff are required to use their critical thinking skills, life, and professional experiences as well as their emotional and ethical being when assessing the needs of their patients (Zaccagnini \& White, 2011). Health care organizations should make this same effort when addressing the needs of the nursing staff. Acknowledging the feelings of employees, respecting their dignity and privacy, and being transparent with organizational matters would foster better relationships between RNs and administration. Open, honest relationships do not always deliver what is expected; however respect and trust is key to sustainment and longevity in any relationship (Kelly, 2007).

The project plan is to develop a program that seeks to create a work environment where RN staff is content with mission, vision and support received by their health care organization. An RN engagement program that increases knowledge, and understanding of the mission, vision, and culture will foster a work environment where RNs are empowered and loyal (Bowers, 2011).

\section{Summary}

The data obtained thus far from researching the engagement of RNs, demonstrates meaningful support for the proposal. This proposal for a $\mathrm{RN}$ engagement forum may not only foster improved communications amongst RNs and hospital administration, it may also hold those organizations who have Magnet Status accountable to sustaining RN engagement with perhaps more frequent NDNQI RN surveys and Magnet visits. This would place emphasis and accountability on health care organizations and systems to sustain programs and systems that support their relationships as well as the tenets of Magnet.

The proposal of such an educational program stands the chance of becoming a standardized expectation throughout health care organizations. Routine committee meetings do 
not attract RNs. While they may attend, attendance is not sustained if they feel their voices are not being heard and repetitive discussions occur about the same topics. Relationship amongst RNs and administration are then jeopardized. If trusting relationships between RNs and administrators are to be established and sustained, and the intent is to connect people with a purpose, the translation of practice and behaviors have to start at the top with role model behaviors (Crum, 2014; Hewison; Richardson \& Storr, 2010; White \& Dudley-Brown, 2012). , Crum, 2014, Richardson \& Storr, 2010, \& Hewison, 2007). 


\section{Section 2: Background and Context}

\section{Concepts, Models, and Theories}

Kolcaba's (2006) comfort theory was the guiding theoretical bases for this proposal. Successful health care organizations that deliver quality care, resulting in positive patient outcomes, and patient satisfaction, owe this success to their RN staff (Heathfield, 2013). The literature reinforces the value of this fact. Engaged RNs will retire from organizations that nurture this type of culture. Being current and involved is key in bonding with the patients you are caring for (Lundin, Paul, \& Christensen, (2000).

Kolcaba began her work on comfort theory in 1988 (McEwen \& Wills, 2011). In 1994, comfort theory was published and has since been revised. Administration expects the RN to be the caregiver. RNs have the same humanistic needs as their patients. Kolcaba, Tilton \& Drouin (2006) note that an organizational culture that addresses the humanistic needs of their RN staff will reap the benefits of one who performs well above the call of duty.

To understand Kolcaba (1991) comfort theory, it was important to recognize the components of the framework. The primary conclusion made by Kolcaba was that, as human beings, a holistic approach should be taken when addressing one's comfort. Those areas noted by Kolcaba are our physical well-being, psychological well being, sociocultural well being and our environments. Kolcaba applied this concept to approaching patients and RNs in a holistic manner. This holistic approach to caring for an individual demonstrates the relationship between needs, interventions and outcomes (Kolcaba, 1995). 


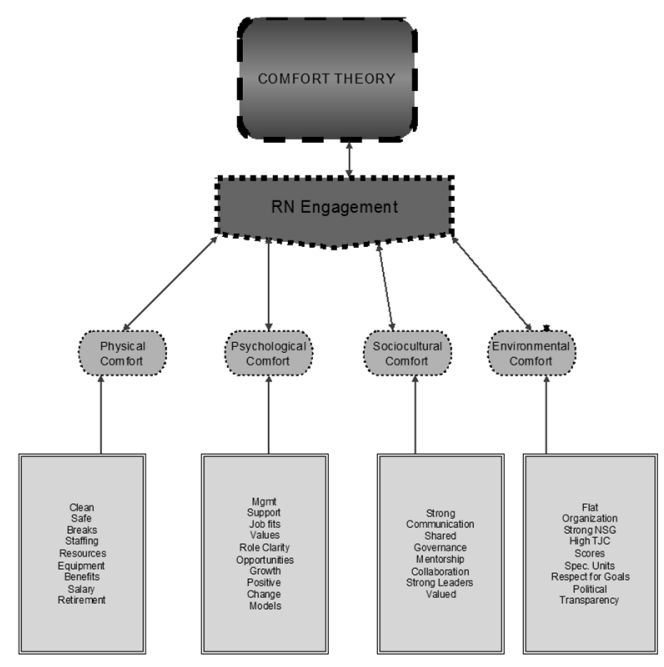

Figure 1. Factors Influencing RN Engagement

\section{Relevance to Nursing Practice}

Kolcaba's (2006) comfort theory provides the guiding theoretical foundations for this proposal and future project. Patient outcomes, patient satisfaction, organizational success and their return on investment will always be dependent upon RN engagement (Heathfield, 2013). The inference is that RN engagement results in loyalty that leads to recommendations and repeat customers. Engaged RNs will stay with organizations that foster this type of culture. Being present and engaged is key to connecting with the patients RNs are caring for (Lundin, Paul, \& Christensen, (2000).

\section{Local Background and Context}

Kolcaba began her concept examination toward the phenomena of comfort theory in 1988 (McEwen \& Wills, 2011). In 1994, comfort theory was published and has since been revised. Like patients, RNs have basic needs. Kolcaba, Tilton \& Drouin (2006) relate this same phenomenon to nursing practice in that their needs, when met, foster a positive outlook on how they perform which enhances the quality of care they deliver. Any health care organization would benefit from comfort theory. 
Employees who are content in their organizational relationship go above and beyond to maintain the organizational mission. Collins, Collins, McKinnies and Jensen (2008) surveyed human resource managers regarding their biggest challenges. The most paramount findings were that of employee turnover rates. Retention and an aging population are areas of concern for any human resource managers, nurse manager, and health care organization. Routinely assessing the needs of the RN staff to find out what they want and need is highly recommended by Geyer, (2005). Kolcaba's comfort theory addresses the needs of the RN as the caregiver and as a human being. These needs are met by an organization that is committed to their relationship with the $\mathrm{RN}$ staff. $\mathrm{RN}$ staff needs to feel safe and secure in their organizational relationship. If concerns such as resources are an issue, RN's will not feel safe. Safe staffing has to be a priority (Bodenheimer \& Grumbach, (2012).

\section{Role of the DNP Student}

My affiliation with the participating practicum environment began in December 2014. This facility has been the site for the my practicum experience. This facility is the intended forum for which the program will be implemented. Due to the small nature of this community hospital, these key stakeholders strongly believe that an $\mathrm{RN}$ engagement program where the administrative team respects RNs as partners in care, would prove appropriate ( KW, DG, and KG, personal communications, February, 2015).

I have been involved in efforts to promote RN engagement since December 2014. A constant theme noted with RN staff is their concerns with available resources and their voices being heard (Grant, Colello, Riehle, and Dende, 2010). Thus, in an effort to initiate change and provide support for the $\mathrm{RN}$ staff, interest for an $\mathrm{RN}$ engagement program was awakened. Authorization from the VP of Nursing allowed the DNP student to have access to and review 
previous NDNQI RN survey data as well as data from the interim survey conducted by the organization. It was very important for me to acknowledge the importance of leadership in its representation of administration as well as advocacy of the RN staff. 


\section{Section 3: Collection and Analysis of Evidence}

\section{Introduction}

Through this project I seek to determine the correlation between the culture of a health care organization and RN engagement. While the organization is designated as a Magnet Model, the actual possession of the characteristics of Magnet cannot be assumed. The sample population to be used in this study is $\mathrm{RN}$ staff from a small community hospital in the upper Hudson Valley area of New York. There is no cap on the number of participants, as more participants will justify the positive correlation (Terry, 2015). This sampling is convenient as it relates to their participation in recent NDNQI RN surveys and upcoming redesignation. Some new employees may not have been involved in the recent surveys.

Participant criteria includes qualifying as the following:

- Registered nurse

- Full time status

- 611 per diem staff

Exclusion criteria includes:

- Part time registered nurses

- Casual per diem registered nurses

- Leadership/Administrative registered $n$

- Nurses

Participation in the NDNQI RN survey is confidential. Although highly encouraged, participation is voluntary with no information highlighting their identity and participation (Grove et al., 2013). 


\section{Practice-Focused Question}

Careful consideration of those factors that promote and hinder RN engagement are important to review (Freeney \& Tiernan, 2009). Once implemented, this project may stimulate social changes in practice and how organizational cultures are developed and sustained. As nurse leaders, we are responsible for constantly assessing our clinical areas and work environments, taking advantage of the available resources that will lead to improvements in our work environments, treatment and processes, as well as patient satisfaction (Hodges \& Videto, 2011). The current health care organization is due for Magnet re-designation. While administration is optimistic, there have been concerns regarding RN engagement. Aside from the May 2014 NDNQI RN survey, there was an interim survey conducted in March 2015. A successful RN engagement program might help alleviate those concerns, as the program will allow for ongoing assessment and evaluation to meet the needs of the RN staff (Grant, Colello, Riehle and Dende, 2010).

The efforts made to nurture and develop a collaborative relationship between administration and RN staff will prove beneficial to all parties, the patient population they serve and the organizations bottom line. With constant changes in health care, nurse leaders are charged with creating strategies that not only foster better outcomes, but also demonstrate sustained improvement (Shirey, 2011). While the concept is new, transformational leadership demonstrates one's ability to take their team from point A to point B (Warrick, 2011). It is always the hope that one's team is engaged and willing to work toward improvement and successful patient outcomes.

One of the most significant changes that could result from an effective RN engagement program is an effective health care environment that consistently provides quality patient care 
and outcomes (Parsons \& Cornett, 2011). If this level of care is a priority in the organization, are they willing to make the commitment to the RN staff that provide such care?

\section{Sources of Evidence}

Nursing education will provide the results of the NDNQI RN surveys. While data will provide information on the various departments within the organization, the focus area for RN engagement will be the inpatient care area. It is important to note that the inpatient care areas have had some significant adjustments in their availability of resources over the past 2 years.

Considerations are being made to propose another interim survey after program implementation. Leadership rounds are an ongoing practice for me. This practice will provide real time feedback from RN staff regarding concerns and challenges. There is no direct patient participation in this project other than the use of their feedback in the Press Ganey and HCAHPS surveys which offers questions specific to:

- Nurses overall

- Courtesy and respect

- Response time

- Careful listening

The guidelines of the Health Insurance Portability and Accountability Act are not of concern as no patients will be involved.

Leadership support was previously been encouraged by the Chief Nursing Officer (CNO). It is important to note that some clinical nurse managers are new to the role and may have previously worked directly with the teams they are now managing. The development of these clinical nurse manager relationships has been challenging due to the various levels of experience with leadership, leadership style and approach to systems changes. Nursing 
education has demonstrated ongoing support. The administrative team has changed significantly at my practicum site. leadership has changed over the past year.

\section{Analysis and Synthesis}

The variables in this project are $\mathrm{RN}$ engagement and organizational culture. These variables are independent of each other (Grove, Burns, \& Gray, 2013). It should be understood that perception can be influenced, not controlled. Hence the RNs interpretation of the questions on the NDNQI RN survey. The online NDNQI RN surveys do not afford the opportunity for me to connect with human feelings. Each participant, $\mathrm{RN}$ and patient may perceive the same questions differently. While there is a plethora of data that demonstrate the positive impact of one variable over another, more research with direct tools and less generalized questions like those on the survey would prove beneficial to the project problem statement.

Governmental and other regulatory agencies have made the expectations clear as it relates to safe, quality, effective health care. The implementation of a program within an organization that intends to remain viable in this competitive health care environment, must assess, design, plan and implement systems that will sustain improvement. The key to sustained improvement is continuous assessment and evaluation of programs and systems (Kettner et al., 2013).

Havelock's theory of planned change offers employees the opportunity to understand and perhaps adjust at a better rate, offering cycles of the process (White \& Dudley-Brown, 2012). One of the most common reasons that change is not sustained is because of what appears to be an ending point. It is the assumed point at which the goals and have been obtained and the stakeholders are often left to proceed. With health care constantly changing, hence organizational changes, it is a never ending process to adjust, change and improve, making the cycle action of Havelock's Theory appropriate. Changes often fail due to processes ending. 
Havelock's process has a renewal phase, which continues to look at improvement. This is how an RN engagement program should look in order to sustain engagement. A quarterly educational module that meets the needs of the $\mathrm{RN}$, fostering engagement, has to constantly evolve.

The long-term plan will be to use the Utrecht work engagement scale once the program is implemented. The evaluation plan for a successful RN engagement program may include the use of a Lickert scale questionnaire containing five to 10 questions, as well as recruitment and retention data. The organization has recently participated in it's NDNQI RN Engagement Survey between June $7^{\text {th }}$ to June $28^{\text {th }}$. It has also participated in a hospital wide employee engagement survey conducted by a third party.

\section{Summary}

The concept of $\mathrm{RN}$ engagement should be the priority of all health care organizations. It is imperative for health care organizations to assess their culture, noting its impact on the ability to recruit and retain engaged RNs (Collins et al., 2008).

Human resources departments are challenged to look at processes when once loyal employees begin to leave an organization. Relationship building efforts on the part of administration makes a strong statement to the RN staff, that administrators care about those matters that are important to them, Kelly (2007). Placing RNs first is not the norm for most health care organization. Those organizations that place their employees first, will reap the benefits of loyal and engaged RN staff (Spiegelman \& Berrett, 2013). 


\section{Section 4: Findings and Recommendations}

\section{Introduction}

The main objective of this project was to demonstrate how organizational culture impacts RN Engagement. With the recent changes in hospital administration, there has been a genuine concern that the culture, being a family like environment, will change. An administrative team who understands change and the fears that come with it, would be most appropriate in it's proactive approach in alleviating these concerns by being present and engaged with the RN staff. This administrative team would continuously live the mission and vision of the organization, respect the importance of the $\mathrm{RN}$ role, acknowledge how the $\mathrm{RN}$ role impacts healthcare and how important the $\mathrm{RN}$ role is in the success of the organization.

\section{Findings and Implications}

During the Nursing Leadership meeting held in early August, it was announced that the 2016 NDNQI RN survey scores were in. Not only were nurse leaders excited to hear their individual unit results, with the impending Magnet re-designation Survey in the fall, everyone wanted to get started on their action plans, moving forward with staff preparation for the Magnet mock survey to be held September $19^{\text {th }}$ and $20^{\text {th }}$. The CNO shared the fact that while most units had demonstrated improvement, one of the significant areas of concern was the presence and visibility of the CNO. With this small community hospital being the only Magnet designated hospital within this now larger organization since their merge in March 2015, the focus was indeed on this community hospital. The main campus had recently taking the necessary steps in applying for their first Magnet designation, there has been a sense of expectancy that the community hospital would be the role model. 
The Magnet Mock survey, later called the Magnet prep survey, was a worthy investment on the part of the organization. While there had indeed been a turn over in staffing with some RN's having never experienced working within a Magnet designated organization, there was a lot to be said for those RNs with a longer tenure, who did not know how to speak to the tenets of Magnet. Not only had the consultant noted this in the presentation of her findings, but she also reiterated the findings from the recent NDNQI RN survey in which some of the RN staff did not know who their CNO was. The implication is clear, the concept of RN engagement should be the priority of all health care organizations.

With the Magnet survey having been completed between, October $19^{\text {th }}$ and the $21^{\text {st }}$, most RNs were relieved and confident that the organization will receive its third redesignation. In consideration of the popular crunch preparation, I too must say that the outcome looks positive. Nevertheless, a lot can be said about how most organizations exemplify the tenets of Magnet.

Nursing has profound contributions to health care are priceless and never ending. Any healthcare organization that lends itself in the prioritization of the RN engagement level, will reap the benefits two fold.

\section{Recommendations}

The evidence is clear in demonstrating how the culture of an organizational can impact $\mathrm{RN}$ engagement. It is therefore my recommendation that an RN Engagement Program be implemented in order to demonstrate the commitment to respecting, supporting and acknowledging the significant role of the $\mathrm{RN}$ in health care changes and organizational success.

\section{Strengths and Limitations of the Project}

The strength of such a project will be based upon the efforts put forth to develop and sustain such a program. The commitment to this relationship between the organization and its 
RN staff will have numerous benefits including RN loyalty, decreased burnout, decreased turnover rates, increased RN satisfaction, increased patient satisfaction, and a positive return on investment for the organization. While and $\mathrm{RN}$ engagement program may not incur a high bill, it would indeed require time and commitment on behalf of nursing and hospital administration. The lack of such commitment may lead to disengaged RN staff and the potential for increased turnover rates (Atkins, et al., 1996). Ongoing assessment of the established goals, and the creation of new goals guided by the needs of the RN staff would prove fundamental to the sustainment of the program. 


\section{Section 5: Dissemination Plan}

The inclusion of key stakeholders is vital to the success of the RN engagement program. While the proposal of an RN Engagement Program was presented to nursing leadership earlier this year, the concept was not shared with upper administration. In consideration of recent administrative changes and the obvious need for relationship building, the recent NDNQI RN survey results from June 2016, the employee engagement survey held from September $7^{\text {th }}$ to September $28^{\text {th }}$, and the recent Magnet Survey conducted October $19^{\text {th }}$ through the $21^{\text {st }}$, it is the perfect time to implement an $\mathrm{RN}$ engagement program.

I would like to prepare a poster board presentation highlighting literature that emphasizes the importance of RN Engagement as well as the scores of the NDNQI RN survey from 2013 to 2015. I would eventually like to be able to conduct one on one surveys, as well as group sessions with the RN staff in order to have some qualitative data, demonstrating the emotional context of RN engagement, tracking trends and connecting those trends with the responses to the NDNQI RN survey. I am optimistic that presenting these finding at nursing leadership and the management meeting would sustain the buy in for the RN engagement program.

The RN engagement program would be a quarterly forum in which nurse leaders would present and get feedback from the RN staff on matters such as:

- Employer of choice

- Best service/growth

- Quality indicators

- Growth/Financial Viability

These pillars are all significant to the viability of the organization, hence important areas of concern requiring the necessary involvement of the RN staff (IOM, 2010). Guest speakers 
such as the CFO, the president and even outside experts would be invited to speak to and with the RN staff. Team building activities, leadership sessions, and open discussions would be part of the design of the RN engagement program. An open and interactive style session to be held quarterly for one and a half to two hours in which RN staff would participate in a program that is solely about them, their significance within the organization and the importance of their voices and expertise in the growth and change necessary for the organization to succeed. In consideration of the workload and dedication of the RN staff who rarely leave the unit, this quarterly forum would sometimes be an on the road program, meeting the RN staff on their units and even at the bedside.

\section{Analysis of Self}

I see myself as the facilitator of the RN engagement program, however more importantly part of a greater team that acknowledges the importance of the $\mathrm{RN}$ role in the health care system. I would like to present this concept at larger venues such as the regional town hall meetings with nurse leaders who are seeking Magnet Designation. While the focus is to present those stories and data that support them as part of the Magnet document application, it is more important that an organization present a nursing team that can speak to the document in a manner that demonstrates pride in what they have done and an attitude content with their organizational relationship.

I began this DNP journey in 2012. Despite the small pauses in my studies due to family matters, my focus remained steady. I have a plethora of experience having worked within health care organizations that remain focused on numbers instead of people. I have been more determined in my research to demonstrate the correlation of organizational culture and $\mathrm{RN}$ engagement. If indeed this is a positive relationship, it will be demonstrated in the success of 
any healthcare organization and sustained by a well-developed and dynamic RN engagement program (Collins, et al., 2008).

The post graduate plan to implement an $\mathrm{RN}$ engagement program is not a matter I take for granted. The challenges faced during this scholarly journey offered many insights that have helped me grow personally and professionally. With the initial acceptance of my DNP Project being from a prior administrative team that knew and trusted my intentions, the sudden change in administrative teams did not initially appear concerning. Considering the topic, my thoughts were that a new administrative team, attempting to build new relationships would see my project as the perfect measure to put into place. Trust seemed to be a factor in getting the buy in, as I perceived the intentions of the project being the main area of concern.

It became important to clarify my intentions with the RN engagement program were to benefit the organization, not my personal or academic agenda. I still believe there are some concerns, despite the letter of cooperation from the CNO. I can only be optimistic that once I present the program to the senior administrative team, the purpose and intent will be clear without question, including the ROI. My plan to better support buy in from the CNO is to demonstrate an emphasis and respect of her opinions and ideas.

\section{Summary}

The concept of an RN engagement program may have actually begun several years into my being a nurse leader. I especially note several years, as it certainly took me some time to learn and grow in this important role. In the process of practicing, learning, listening, and observing, my professional nursing path has afforded me the opportunity to impact the lives of others in a way that no other healthcare professional can. Although healthcare continues to change, the essence of the human connection made between healthcare consumers and the RN 
staff that care for them never changes. It is the RN staff that makes themselves vulnerable and available to address the physical, emotional, psychological, and spiritual needs of patients and families. These frontline stakeholders are the everyday heroes that change lives, even when death is imminent. Any healthcare organization that values the worth of an RN, knows that these RN's need just as much support as the patients they serve. Healthcare organizations willing to invest in an RN engagement program, will demonstrate a commitment to their RN staff and ultimately the communities they serve. This win-win approach affords a healthcare organization a competitive edge in safe, quality, effective care that is rendered by present and engaged RN staff who are committed and loyal to their healthcare organizations. 


\section{References}

American Association of Colleges of Nursing. (n.d.). Future of the nursing: Leading change, advancing health: A report from the Institute of Medicine (IOM) and the Robert Wood Johnson Foundation.

Atkins, M., Marshall B., \& Jvalgi, R. (1996). Happy employees lead to loyal patients. Journal of Healthcare Marketing.

Bae, S. (2012). Nursing overtime: why, how much, and under what working conditions. Nursing Economics. 30 (2), 60-71.

Bae, S., \& Brewer, C. (2010) Mandatory overtime regulations and nurse overtime. Nursing Practice, 11(2) 99-107. doi: 10.1177/1527154410382300.

Bakker, A., \& Demerouti, E. (2008). Toward a model of work engagement. Career Development International, 13(3), 209-223.

Ball, M., Douglas, J., \& Hinton-Walker, P. (2011). Nursing Informatics, where technology and caring meet $\left(4^{\text {th }}\right.$ ed.). New York: Springer -Verlag London.

Bodenheimer, T., \& Grumbach, K. (2012). Understanding health policy: A clinical approach (6th ed.). New York, NY: McGraw-Hill.

Boev, C. (2012). The relationship between nurses' perception of work environment and patient satisfaction in adult critical care. Journal of Nursing Scholarship, 44(4), 368-375. doi: $10.1111 / \mathrm{j} .1547-5069.2012 .01466 . x$

Bowers, B. (2011). Managing change by empowering staff. Nursing Times, 107(32/33), 19-22.

Buerhaus, P., Staiger, D., \& Auerbach, D. (2003). Is the current shortage of hospital nurses ending? Trends, 22(6). 191-198. 
Burston, P., \& Stichler, J. (2010). Nursing work environment and nurse caring: relationship amongst motivational factors. Journal of Advanced Nursing, 1819 - 1828.

Clarke, S., \& Aiken, L. (2008). An international hospital outcomes research agenda on nursing: lessons from a decade of collaboration. Journal of Clinical Nursing, 17, 3317 -3323. doi: 10.1111/j.1365-2702.2008.02638.x

Collins, K., Collins, S., McKinnies, R., \& Jensen, S. (2008). Employee satisfaction and employee retention, catalysts to patient satisfaction. The Health Care Manager, 27(3), $245-251$

Crum, R. (2014). Motivating executives, leaders, and policy-makers to address the nursing shortage. Charting nursing's future policy brief series. Robert Wood Johnson Foundation. Retrieved from http://www.rwjf.org/en/research-publications.

Fasoli, D. (2010). The culture of nursing engagement, a historical perspective. Nursing Administration Quarterly, 34(1), 18-29.

Freeney, Y., \& Tiernan, J. (2009). Exploration of the facilitators of and barriers to work engagement in nursing. International Journal of Nursing Studies, 46, 1559-1565.

Geyer, S., (2005). Hand in hand, patient and employee satisfaction. Trustee, 12-19.

Ginter, N. (2014). Promoting RN satisfaction with a program for novice nurses. Walden University, DNP Doctoral Dissertation.

Grant, B., Colello, S., Riehle, M., \& Dende, D. (2010). An evaluation of the nursing practice environment and successful change management using the new generation Magnet Model. Journal of Nursing Management, 18(3), 326-331. doi: 10.1111/j.13652834.2010.01076.x. 
Grosfield, J., Polk, H., Pelligrini, C., Mulholland, M., Lillemoe, K., Mass, B., Busuttil, R., Kron, I., Jones, R., Townsend, C., \& Sheldon, G. (2007). The health workforce, a position statement. Annals of Surgery, 246(4), $525-526$.

Grove, S., Burns, N., \& Gray, J. (2013). The practice of nursing research, appraisal, synthesis, and generation of evidence ( $7^{\text {th }}$ ed.). St. Loius, Missouri: Elsevier Saunders.

Heathfield, S. (2013, March). Employee satisfaction. About.com. Retrieved from http://humanresources.about.com/od/employeesurvey1/g/employee.

Hewison, A. (2007). Policy analysis: a framework for nurse managers. Journal of Nursing Management, 15, 693-699.

Hodges, B., Videto, B. (2011). Assessing and planning in health programs. Sudbury, MA, Jones $\&$ Bartlett Learning.

Hunt, S. (2007). Hiring success: the art and science of staffing assessment and employee selection. San Francisco, Ca. Pfeiffer.

Hyrkas, K., \& Harvey, K., (2010). Leading innovation and change. Journal of Nursing Management, 18(1), 1-3.

Institute of Medicine, (2010). The future of nursing, focus on education. Report Brief. Health Resources and Services Administration.

Institute of Medicine. (2010). The future of nursing, leading change, advancing health. Report Brief, Health Resources and Services Administration.

Jones, C., \& Gates, M. (2007). The cost and benefits of nurse turnover: a business case for nurse retention. Medscape, 12(3). Retrieved from http://www.medscape.com/viewarticle/569393

Kelly, M. (2007). The dream manager. New York: Beacon Publishing. 
Kennedy, M. (2015). Revisiting patient satisfaction surveys, are hospitals using the results properly? American Journal of Nursing, 115(8).

Kettner, P. M., Moroney, R. M., \& Martin, L. L. (2008). Designing and managing programs: An effectiveness-based approach ( $3^{\text {rd }}$ ed.). Thousand Oaks, CA: Sage.

Kolcaba, K., Tilton, C., \& Drouin, C. (2006). Comfort theory, a unifying framework to enhance the practice environment. JONA, 36(11), 538-544.

Kotter, J. (2007). Leading change, why transformation efforts fail. Harvard Business Review, 96104.

Lambrou, P., Merkouris, A., Middleton, N., \& Papastavrou, E. (2014). Nurses' perception of their professional practice environment in relation to job satisfaction: a review of quantitative studies. Health Science Journal 8(3), 3-7..

Lundin, S., Paul, H., \& Christensen, J. (2000). Fish. New York: Hyperion.

Manley, K., Sanders, K., Cardiff, S., \& Webster, J. (2011). Effective workplace culture: the attributes, enabling factors and consequences of a new concept. International Practice Development Journal, 1(2), 1-29.

Oerman, M. \& Hays, J. (2016). Writing for publication in nursing. ( $3^{\text {rd }}$ ed.). New York, Springer Publishing Company.

Parsons, M. \& Cornett, P. (2011). Leading changes for sustainability. Nurse Leader, 9(4)36-40.

Pfaff, K., Baxter, P., Ploeg, J., \& Jack, S. (2014). A mixed methods exploration of the team and organizational factors that may predict new graduate nurse engagement in collaborative practice. Journal of Interprofessional Care, 28(2), 142-148. doi: 103109/13562820/2012

Radtke, K. (2013). Improving patient satisfaction with nursing communication using bedside shift report. Retrieved March 16, 2015, from www.medscape.com/medline. 
Richardson, A., \& Storr, J. (2010). Patient safety: a literature review on the impact of nursing empowerment, leadership and collaboration. The Authors. Journal Compilation, International Council of Nurses, $12-21$.

Schifalacqua, M., Mamula, J., \& Mason, A. (2011). Return on investment imperative, the cost of care calculator for an evidence-based practice program. Nursing Administration Quarterly, 35(1), 15-20.

Shirey, M. (2011). Establishing a sense of urgency for leading transformational change. Journal of Nursing Administration, 41(4), 145-148.

Spiegelman, P. \& Berrett, B. (2013). Patients come second. New York: Greenleaf Book LLC.

Studer, Q. (2003). Hardwiring excellence, purpose, worthwhile work, making a difference. Gulf Breeze, FL. Fire Starter Publishing.

Terry, A. J. (2015). Clinical research for the doctor of nursing practice. (2nd ed.). Burlington, MA: Jones \& Bartlett Learning.

Tillott, S., Walsh, K., \& Moxham, L. (2013). Encouraging engagement at work to improve retention. Art \& Science, Workplace Culture.

Tomey, A. (2009). Nursing leadership and management effects work environments. Journal of Nursing Management, 17(1), 15-25. doi: 10.1111/j.13652834.2008.00963

Warrick, D.D. (2011). The urgent need for skilled transformational leaders: integrating transformational leadership and organizational development. Journal of Leadership, Accountability and ethics, 8(5), 11-19.

Watson, E., \& Hillman, H. (2010). Advanced practice registered nursing: licensure, education, scope of practice, and liability issues. Journal of Legal Nurse Consulting, 21(3), 25 - 28. 
White, K. M., \& Dudley-Brown, S. (2012). Translation of evidence into nursing and health care practice. New York, NY: Springer.

York, G., Jones, J., \& Churchman, R. (2009). Understanding the association between employee satisfaction and family perceptions of the quality of care in hospice service delivery. Journal of Pain and Symptom Management, 38(5), 708-714.

Zaccagnini, M., \& Waud-White, K. (2011). The doctor of nursing practice essentials, a new model for advanced practice nursing. Sudbury, MA: Jones and Bartlett Publishers. 